\title{
UM PROJETO DE MULTIPLICIDADE ENTRE PESQUISA, EXTENSÃO, UNIVERSIDADE E COMUNIDADE: VIVENCIANDO A CULTURA NO BAIRRO RESTINGA
}

\author{
Elisângela Zaniol ${ }^{\star}$ \\ Fábio Dal Molin ${ }^{\star \star}$ \\ Giovani Andreoli $i^{\star \star}$
}

\begin{abstract}
Resumo
A proposta deste estudo é analisar os processos de construção de um campo de abertura institucional e de integração do ensino, pesquisa e extensão, a partir de uma posição heterogênea de intercessores e pesquisadores em um projeto de extensão desenvolvido entre a universidade e oficineiros do bairro Restinga em Porto Alegre. São observados movimentos sistêmicos entre: Ensino/Pesquisal Extensão,Universidade/Comunidade, Sociologia/Comunicação/Psicologia Social, Juventude/Vulnerabilidade Social, Escola/Violência. A partir da pesquisa-intervenção produziu-se uma análise das possibilidades e conflitos nas atividades do projeto, no estabelecimento de câmbios estruturais entre seus elementos, auxiliando na sua manutenção como sistema pela produção de si mesmo.
\end{abstract}

Palavras-chave: Oficinas. Juventude. Violência. Interdisciplinaridade. Pesquisaintervenção.

\section{A MANifold PRojeCt BETWEen RESEARCh, EXTENSION, UNIVERSITY AND COMMUNITY: EXPERIENCING CULTURE IN RESTINGA DISTRICT}

\footnotetext{
* Psicóloga, Mestre em Psicologia Social e Instituicional pela Universidade Federal do Rio Grande do Sul. Áreas de pesquisa/intervenção: Projetos Sócio-Educativos, Tecnologias e Informática Educativa.

E-mail: elisangelaz@yahoo.com.br

$\star \star$ Psicólogo, Mestre em Psicologia Social e Institucional pelo PPGPSI UFRGS Doutor em Sociologia UFRGS. Áreas de pesquisa/intervenção: Subjetividade, Redes Sociais, Conflitualidade e Lutas Sociais Contra a Violência. Endereço Rua Professor Álvaro Alvim 445/403 - Bairro Rio Branco. CEP 90420-020, Porto Alegre-RS.

E-mail: fmolin@portoweb.com.br.

$\star \star \star$ Psicólogo Clínico e Social, Mestre pelo Programa de Pós-Graduação em Psicologia Social e Institucional da Universidade Federal do Rio Grande do Sul, editor do sítio eletrônico "ONIROS: Arte \& Clínica - Psicologia" em www.oniros.com.br.

E-mail: andreoli@dr.com
} 


\begin{abstract}
The objective of this study is to analyze the processes of the construction of an institutional access field and integration of education, research and extension, from a heterogeneous position of intercessors and researchers in an extension project developed between the university and workshop instructors of the Restinga district in Porto Alegre. Systemic movements between Education/Research/ Extension, University/Community, Sociology/Communication/Social Psychology, Youth/Social Vulnerability, School/Violence were observed. From the researchintervention an analysis of the possibilities and conflicts in the activities in the project, in the establishment of structural exchanges between their elements, assisting in its maintenance as a system through the production of itself.
\end{abstract}

Keywords: Workshops. Youth. Violence. Interdisciplinary. Research-intervention.

\title{
DelimitaÇão de CAMPOS DE PODER
}

Boaventura de Sousa Santos (2003), no livro Pela Mão de Alice, faz interessantes considerações sobre o papel da universidade e seus contínuos movimentos de aberturas e clausuras, no decorrer da história, e da sua função de formação da elite intelectual, ou de produção de conhecimentos, até sua explosão no século XX. A instituição universitária, talvez uma das mais conservadoras instituições ocidentais ainda em atividade, tem sido objeto de discussões e inúmeras propostas de reforma, e, no seu cotidiano, pelo trabalho de seus atores, vem produzindo diferentes modos de interação com a comunidade. Às considerações de Boaventura, pretendemos relacionar uma concepção sistêmica da universidade, observando seus movimentos reticulares de interseção e as perturbações mútuas entre universidade e comunidade.

A proposta deste estudo é analisar os processos de construção de um campo transdisciplinar, de abertura institucional e de integração das funções ensino, pesquisa e extensão, que investigamos a partir de uma posição heterogênea de intercessores e pesquisadores dos campos da Psicologia e da Sociologia. Busca-se observar o fenômeno como unidade integradora de campos sociais em conflito e formadora de um sistema complexo que opera coletivamente na solução de problemas. São observados diferentes movimentos sistêmicos de acoplamento: ensino/pesquisa/extensão, universidade/comunidade, sociologia/comunicação/psicologia social, arte/política, juventude/vulnerabilidade social, escola/comunidade, escola/violência. É possível produzir uma análise das possibilidades e dos conflitos na atividade universitária e estabelecer câmbios estruturais entre seus elementos componentes, auxiliando na sua manutenção como sistema pela produção de si mesma (determinismo estrutural sistêmico) pela incorporação de novas estratégias, através de mútuas perturbações com a comunidade. São importantes aqui os conceitos de regulação/emancipação de Boaventura (SANTOS, 2003), de determinismo estrutural sistêmico de Maturana e Varela (2001), e de transversalidade de Guattari (1998). 


\section{O PROJETO "VIVENCIANDO A CULTURA NA RESTINGA" EM UMA PERSPECTIVA SISTÊMICA}

O início deste projeto surgiu pela conexão entre dois grupos: na Psicologia Social e Institucional da UFRGS o "Juventude e Contemporaneidade", e na zona sul de Porto Alegre o "Fórum das Escolas do Bairro Restinga".

O projeto de extensão universitária chamado "Juventude e Vulnerabilidade Social: Oficinando com Adolescentes", que acabou, em intensas discussões sobre o estigma do termo "vulnerabilidade", por metamorfosear-se em "Vivenciando a Cultura na Restinga" permitiu a efetivação de algumas propostas de atuação da universidade a partir de sua condição contemporânea, tanto num nível de câmbios em sua estrutura (que são os elementos constituintes de sua organização), quanto no nível de suas relações com outros sistemas.

O projeto durou quase três anos, e foram realizadas quase cem reuniões de planejamento e avaliação, oficinas, visitas, sendo produzidos um vídeo em curta metragem e o livro Vivenciando a Cultura na Restinga (PACHECO et al., 2007).

Ambos são estados emergentes, resultantes de diferentes pontos de vista e de atuação em interseção. Na UFRGS surge a demanda pela integração da Universidade com projetos relacionados à juventude e segurança pública a partir de pesquisadores universitários e profissionais interessados em compartilhar experiências, o que potencializa a estrutura da academia. Uma rede de pesquisadores foi constituída enquanto fluxo organizado de informação e interação exploratória.

A Restinga é um bairro localizado na zona sul de Porto Alegre, criado nos anos 60 sob a estratégia de isolamento geográfico de populações de periferia econômica (tornada, portanto, periferia espacial). Sua história é, basicamente, uma história de exclusão, pois sua gênese é em um programa governamental de remoção de comunidades do centro para fora dos limites da área urbana eufemisticamente nomeado "Remover para Promover" (NUNES, 1990). Ainda que as condições de vida do bairro tenham melhorado significativamente em muitos aspectos (acesso à água encanada, transporte, luz elétrica), este apresenta um percentual considerável de população favelada e índices de renda e criminalidade altos em relação às médias nacional, estadual e municipal.

A população predominante da Restinga é o jovem e de baixa renda (OBSERVAPOA, 2007), e as taxas de homicídio encontram-se entre as mais elevadas da capital. Porém, esta criminalidade violenta apresenta, em um olhar mais complexo, aspectos localizados e específicos, pois, concomitantemente, a Restinga é pioneira na cidade na constituição de uma Rede de Atenção à Criança e ao Adolescente, e bastante atuante no programa do Orçamento Participativo (criado pela administração popular na prefeitura municipal de Porto Alegre no início dos anos 90), além de possuir um Fórum das Escolas há quatro anos. Por outro lado, seus intercâmbios com a instituição universitária iniciaram-se pela via micropolítica dos estagiários que buscavam espaço de atuação, aprendizado e pesquisa em instituições como creches, escolas, o posto de saúde e o centro comunitário, além da 
própria rede de atendimento. As pesquisas iniciais foram feitas por mestrandos, doutorandos, e estagiários da UFRGS.

Neste contexto paradoxal de vulnerabilidade e expansão da cidadania dos habitantes locais, os oficineiros ${ }^{1}$ têm constituído uma força comunitária importante de atuação social, implicados voluntariamente em interagir dentro do sistema da comunidade, ocupando posições intermediárias e ambivalentes com relação aos tradicionais órgãos públicos. Ainda que suas intervenções sejam na maioria das vezes em escolas ou sejam patrocinadas pelo poder público, os oficineiros, sendo alguns também líderes comunitários ou até mesmo professores de escolas, atuam em espaços intersticiais na comunidade, explorando a relativa liberdade em relação às instituições que a atravessam.

Para o pensamento sistêmico dos biólogos Maturana e Varela (2001), o tecido social se fundamenta nas trocas estabelecidas a partir dos laços afetivos, sobre os quais o exercício da ética, entendida como a consideração e compreensão do outro, é a condição para que grupos humanos mantenham-se, conservando-se e transformando-se ao longo do tempo, como todos os processos vitais próprios de uma coletividade. As emoções, ou trocas de afetos, são aqui entendidas como a fonte de toda a atividade humana pois, antes de tudo, somos seres vivos, somos animais: emoções "são disposições corporais dinâmicas que especificam os domínios de ações nos quais [...] operamos num instante" (MATURANA; VARELA, 2001, p. 129).

Partimos da concepção de sujeito que se constitui enquanto potência cognitiva nas interações de um coletivo, dentro de "uma coexistência comunitária que dá origem a uma rede de interações recorrentes, que resulta num modo de vida no qual surge o linguajar" (MATURANA, 1997, p. 229).

Um sistema é o que um observador gera em sua ação/existência/conhecimento de observador (os três são simultâneos, nenhum prescinde do outro), ou seja, um sistema existe como resultado da operação de um sujeito.

Observar é o que nós, observadores, fazemos ao distinguir na linguagem os diferentes tipos de entidades que trazemos à mão como objetos de nossas descrições, explicações e reflexões no curso de nossa participação nas diferentes conversações em que estamos envolvidos no decorrer de nossas vidas cotidianas, independentemente do domínio operacional em que acontecem. (MATURANA; VARELA, 2001, p. 126)

No caso dos elementos constituintes do projeto, é importante observar os que são criadores e mantenedores dos laços afetivos. A preocupação dos oficineiros da Restinga com as condições de vida dos jovens do bairro e o desejo de cooperação e democratização do saber acadêmico dos pesquisadores/extensionistas demonstram que as emoções motivadoras envolvidas gerenciam os grupos e recursos de modo a preservar a organização do subsistema das oficinas dentro do sistema maior da comunidade, determinando as relações a partir da própria estrutura (no seu acoplamento com o meio circundante). Igualmente, podemos observar a dedicação dos participantes no trabalho de formação e no aprendizado mútuo, 
buscando uma relação de colaboração, destituindo de importância prática quase que completamente os lugares (formalmente utilizados) de "acadêmico" e de "oficineiro" ao longo do andamento deste trabalho.

A série de encontros realizados entre nós (pesquisadores/extensionistas) e eles (oficineiros) desenvolveu-se por uma rede de conversações em domínios consensuais de uma temática transversal: a necessidade, possibilidade e intenção de construção de um saber híbrido e transdisciplinar, no qual o saber acadêmico e o saber popular pudessem operar em ciclos de retroalimentação geradores de mecanismos de transformação tanto no ambiente acadêmico quanto da vida comunitária. A mobilização de uma série de máquinas humanas, as visitas dos pesquisadores ao bairro, dos oficineiros à universidade e os diversos encontros ao longo de um ano formaram laços recursivos, grupalidades, campos comuns de conflitos e debates, perturbações em modos de trabalhar e de subjetivar costumeiramente assumidos.

Nós, seres humanos em nossos coletivos, grupos, sociedades, existimos através de sistemas simbólicos como domínios lingüísticos em fluxos de pró e retroação de informação, através de nosso histórico de interações e transformações (ontologia). Em nossa constituição lingüística, somos capazes de interagir em domínios simbólicos através de nossos acoplamentos com instrumentos de comunicação "externos" ao corpo, como livros, redes de computadores, aparelhos audiovisuais, etc. no sentido de serem produtos e produtores das nossas ações e constituintes dos nossos corpos "mais amplos" (para além da pele, todos os aparelhos que envolvem o organismo biológico estrito e dele participam, que meios contínuos de manutenção e interação cognitiva). Explicando desta forma, somos híbridos em nossas configurações biotecnológicas contemporâneas.

Observamos aqui estes coletivos emergentes como sistemas compostos, com sua estrutura e sua organização arranjadas em subsistemas de diferentes graus de complexidade, dotados de clausura operacional e abertura ao fluxo de elementos heterogêneos (as instituições estatais, os seres humanos, as instalações físicas, os materiais de consumo, o alimento, os meios de comunicação e registro, as identidades, as estratégias e improvisos, etc.), interagindo com o meio circundante em uma dinâmica de acoplamentos direcionados para manter-se como sistema em seu determinismo estrutural. Ao distinguirmos um grupo de códigos de partilha relativamente estáveis e sua manutenção enquanto uma identidade observável pela descrição explicativa de um observador específico, configuramos um sistema, que pode ser heterogêneo e composto e, ainda assim uma unidade sistêmica.

O grupo componente do projeto "Vivenciando a Cultura na Restinga" pode ser observado como uma identidade sistêmica, ou seja, somos capazes de definir o que ele é a partir de descrições sobre os espaços de interação característicos de seu funcionamento, as reuniões grupais presenciais e a manutenção de seu histórico de interações pelo registro escrito e audiovisual, compartilhado em uma rede telefônica e informática que permite a reflexão contínua sobre o conteúdo reunido. O projeto pode ser visto como uma rede sócio-cognitiva capaz de interagir interna e externamente, e de solucionar problemas (MORIN, 1996) por câmbios em sua estrutura. 
Como sistema composto e relativamente aberto, o grupo pode anexar outros elementos, modificá-los, considerando-os como parte dele mesmo; e igualmente, ao longo de sua história, pode perder elementos que o constituem. Deste modo, a saída de algum dos integrantes dos grupos componentes do sistema chamado "Oficinas da Restinga" também pode ser lido enquanto perturbações que vão obrigar o sistema a se atualizar. Com seu determinismo estrutural (condição subentendida na definição de um "sistema"), sofre a partir do meio apenas perturbações, as quais o motivam a criar suas novas configurações.

Esta característica dos sistemas de existirem como determinados por sua própria dinâmica estrutural e sofrerem perturbações do meio manifesta-se como um fluxo e contrafluxo de energia, em uma luta (ou, melhor dizendo, em uma tarefa) contra a desintegração. Podemos explicá-la através da noção de comunicação da cibernética, que considera a conservação da informação de um sistema como propícia ao seu melhor funcionamento, enquanto as falhas comunicativas seriam componentes fora do controle, o "ruído"; a informação e o ruído acabam estabelecendo uma espécie de "equilíbrio longe do equilíbrio", ou um equilíbrio dinâmico. Neste modelo, "ruído" é um elemento desagregador do sistema, mas também é aquilo que faz com que ele se reconfigure e se torne mais criativo para enfrentá-lo.

No pensamento sistêmico de Maturana e Varela, linguajar é operar o "ruído" como "regra", por assim dizer, e não como "exceção" ou "falha" na comunicação; isso o distancia bastante da noção de comunicação da cibernética acima citada. Porém, a noção de equilibração sistêmica é muito semelhante, e pode servir comparativamente. Um sistema que determina sua estrutura seguinte a partir de sua estrutura prévia (determinismo estrutural) através de uma dinâmica estrutural contínua, na medida em que conserva a sua organização (sua identidade) e o seu acoplamento estrutural (sua relação com o meio), busca renovar-se diante das pressões e obstáculos do meio: nem determinado por condições externas, nem independente delas.

Por exemplo, na Informática, as inovações constantes surgem para dar conta de determinadas tarefas e para suprir a demanda do mercado mundial - ou seja, para resolver problemas em um e outro domínios (instrumental e econômico). O uso da informática mostra falhas e novas necessidades para que se criem novas soluções; são justamente as dificuldades que movimentam os sistemas e os tornam mais criativos e complexos.

\section{Primeiro movimento SISTÊMico: heterogeneidade-Unidade}

O que identificamos como o início do projeto com os oficineiros da Restinga foi justamente uma perturbação exercida sobre um sistema, um grupo de extensão acadêmica denominado "Juventude e Contemporaneidade".

Este grupo funcionava como um conjunto não-fixo de professores e estudantes de diferentes instituições universitárias (em sua maioria da universidade federal, por ser a sede da proposta) e de níveis hierárquicos distintos (graduação, 
pós-graduação, mestrado, doutorado, professores, e mesmo colaboradores pósacadêmicos vinculados extra-institucionalmente), com interesses em comum em suas áreas específicas de atuação (pesquisa, intervenção, estágio curricular, orientação, discussão, escrita de trabalhos finais, etc). A proposta do grupo era o encontro, a troca, sem que houvesse necessariamente um objetivo instrumental imediato; uma condição heterogênea funda a possibilidade de uma unidade relativamente fechada, destoante com a maioria das atividades desenvolvidas no meio acadêmico.

A perturbação foi provocada por um edital da pró-reitoria de extensão, diante do qual fez o grupo se dissociou e reorganizou: uma parte dele formou um outro sistema para colocar em prática o projeto, enquanto as "partes restantes" acabaram por afastar-se progressivamente de qualquer atividade compartilhada. Inicialmente, isto provocou confusão, e muitas discussões foram realizadas para deixar claras as identidades do projeto e do grupo. O grupo é, portanto, inicialmente constituído por uma complexidade de investigadores buscando um domínio comum de interações, um domínio operativo cuja estrutura ligasse as especificidades da psicologia institucional, da comunicação, da sociologia, das artes plásticas (áreas de atuação dos integrantes). Uma das tarefas do sistema passou a ser acoplar-se aos oficineiros da Restinga em torno da sua integração ao projeto; foram necessárias interações comunicativas no sentido de disseminar uma idéia base, uma espécie de sistema operacional que fosse consensual e constituísse funcionalidade no encontro de outros dois. O edital da pró-reitoria de extensão operou significativamente com um "atrator", catalisando desejos imanentes em um aumento da clausura operacional destes sistemas, a fim de que o grupo constituísse uma identidade "da Universidade" e pudesse co-existir na relação com algo "de fora".

No segundo momento, um processo semelhante ocorreu com os oficineiros da comunidade do bairro Restinga. Uma perturbação em seu funcionamento habitual foi provocada não somente pela chegada dos acadêmicos propriamente, mas mais ainda (e ao longo do tempo, no decorrer das conversas) pela proposta altamente inusitada, distanciada das formas habituais com que os agentes acadêmicos se aproximam de um campo de estudo e/ou intervenção: uma busca por parcerias.

\section{SEGUNDO MOVIMENTO: ACOPLAMENTO ESTRUTURAL SISTÊMICO}

As duas primeiras reuniões presenciais foram conturbadas, pois os dois sistemas distintos aqui da academia e da comunidade - precisavam constituir os seus consensos em recursão através de uma história, de uma ontologia própria, produzindo acoplamento estrutural e construindo, neste trajeto, o domínio de interações chamado projeto de parceria.

Em outras palavras, considerando-se a opção inicial dos idealizadores do projeto, um caminho mais longo e difícil foi sendo desenvolvido: a noção de "parceria" com a qual se buscava trabalhar tinha como referência central o respeito às condições, necessidades e saberes presentes tanto na academia, quanto na comunidade. Por isso podemos dizer que este projeto foi montado no pressuposto do determinismo estrutural dos sistemas, ao distinguir ambos os sistemas não somen- 
te como capazes de regerem a si mesmos pelas próprias regras como, mais importante, que respeitar esta determinação seria o melhor caminho para obter resultados válidos a ambos os sistemas.

Neste sentido, evitamos ao máximo a pré-determinação dos encontros com um plano de atividades previamente estabelecido. E isso é mais difícil não somente porque exige mais atenção a cada passo, revisão de atitudes e rumos a cada instante, e sim principalmente porque nenhum dos sujeitos participantes dos dois sistemas distintos estava habituado a esta forma de encontro.

No início, tinha-se a impressão de um "ruído predominante", o que é comum na ausência inicial de consensos. Encontramos apoio em domínios subjacentes, os quais podemos listar: o contexto social onde se desenvolvem os trabalhos e estudos nos quais se incluem os sujeitos participantes; os objetivos gerais presumíveis de todos os agentes envolvidos no processo; algumas histórias de parcerias e encontros anteriores, "em paralelo", de sujeitos entre si através de outros projetos (pesquisas, estágios, etc.), ou mesmo na vida social;

Com o tempo, tínhamos a impressão de que as informações passavam a carregar cada vez mais sentidos comuns, derivando no primeiro (e fundamental) aspecto da parceria buscada: a manutenção da comunicação verbal. As diferenças são o elemento central, neste entendimento, para que ambos os sistemas possam, diante das perturbações a ele oferecidas, transformar-se, gerando perguntas e aprendizado sobre o outro. Estabeleceram-se consensos no conversar que deram margem ao surgimento de sentidos comuns.

O grupo "Oficinas da Restinga" acabou surgindo como um sistema composto, o "projeto de extensão", com diferentes subsistemas de pertencimento dos sujeitos envolvidos: encontros presenciais terças-feiras e sábados; sujeitos inscritos como da academia e/ou da comunidade Restinga; áreas de interesse (de prática e/ou estudo) pessoal específico; graus de participação, em tempo de dedicação ou em setores de atuação; etc.

\section{A micropolítica e o determinismo estrutural}

Pierre Bourdieu (1996) construiu uma teoria baseada não em classes sociais, mas em campos de poder gerados por aquilo que chama de habitus. Os habitus são ações dos indivíduos ou de instituições que vão gerar, ou são geradas, por disputas de valores diversos, e que vão estruturar-se ou serem estruturadas a partir das relações de capital simbólico. O poder, para o autor, é exercido em relações de disputas em campos semelhantes que geram capitais simbólicos.

O capital simbólico pode adquirir diversas formas, dependendo do campo de disputa: financeiro, cultural, moral, religioso. Determinados campos de poder podem gerar o que Bourdieu chama de "doxa", que são as relações reificadas entre dominados e dominantes.

A dominação não é o efeito direto e simples da ação exercida por um conjunto de agentes (a classe dominante) investidos de poderes de coerção, mas o efeito indireto de um conjunto complexo de ações que se engendram na rede cruzada de 
limitações que cada um dos dominantes, dominado assim pela estrutura do campo através do qual se exerce a dominação, sofre de parte de todos os outros. (BORDIEU, 1996, p. 15)

Os oficineiros apresentaram a dicotomia saber acadêmico/saber popular em seu desejo de defesa de que ali os detentores do capital simbólico são eles, por serem da comunidade. Provavelmente já aconteceram, e acontecem, disputas em relação aos adolescentes (enquanto público alvo), originadas por intervenções do estado, que detém capital político e econômico para "atropelar" quaisquer iniciativas com base no capital simbólico da comunidade.

As escolas são um dos melhores exemplos de uma instituição cuja estrutura de poder é a dominação simbólica sobre uma comunidade, e constituem uma "doxa", já que é um dogma mundial que as crianças e adolescentes devem freqüentá-la. Mas a escola, em sua maneira tradicional de funcionar, acaba gerando o que Bourdieu (1989) chama de violência simbólica, pois representa um poder esmagador, que gera sofrimento e imposição de regimes de verdade.

Pelo que percebemos no contato com os oficineiros, as escolas públicas do bairro enfrentam sérios problemas de violência e desagregação social, e buscam alternativas "extracurriculares", já que o capital simbólico do Estado que as gerou parece sucumbir no conflito com a comunidade que as circunda e habita. No caso do tráfico de drogas, por exemplo, o capital simbólico da cultura escolar e das praticamente inexistentes relações de emprego são ineficazes para contrapor a doxa do tráfico de drogas; este envolve uma teia muito forte de relações comunitárias nas quais portar uma arma e ter o poder de matar, executar ordens, ser temido e ganhar uma "boa grana fácil" parecem tornar ridículas as aulas, a disciplina formal.

A questão da vulnerabilidade social, da segurança e da violência tangencia o trabalho dos oficineiros da Restinga, direcionando seus métodos e suas práticas. Estão envolvidos ali adolescentes que vivem em um ambiente em que o tráfico de drogas estabelece um território simbólico de enorme influência. A sociologia de Bourdieu é um exemplo interessante de análise das relações macropolíticas, que é por sua vez saber acadêmico; cabe a nós avançar na dimensão micropolítica (GUATTARI, 1980; DELEUZE; GUATTARI, 1996), no plano de intervenção, pela parceria produzida em/produtora de espaços ambivalentes, paradoxais e, esperamos, complementares.

Os oficineiros estão, por definição, inseridos em espaços comunitários "entre" escolas e instituições, visto que alguns já estiveram ou estão dentro e fora delas, transitando pelas bordas e "atravessando paredes". Foi-nos relatada uma história: uma vez um oficineiro comunitário "tomou uns tragos" e caiu na calçada; algum "esperto" roubou o celular dele e foi trocar na "boca"; o traficante dono da "boca" fora aluno de uma das suas oficinas e, ao ver o nome no celular, mandou o ladrão devolver e pedir desculpas. Esta breve narrativa é uma situação de violência concreta, entretanto também serve para demonstrar que existem espaços de convivência além da distinção binária crime/não crime, e que alguns oficineiros, na sua participação no cotidiano da comunidade, possuem um tipo de inserção que 
nos parece singular, do nosso ponto de vista de acadêmicos pertencentes à classe média, com nossas noções formais de regulação criminal adquiridas, principalmente, na escola e na grande mídia.

Atualmente, há correntes de criminólogos atentos a este tipo de relação, que envolve violência ou delito, mas escapa à esfera da lei penal. Citamos Van Swaaningen (2003, p. 32): "Os advogados criminais ainda parecem acreditar mais que o caos e a anarquia da sociedade serão completos se a lei não estiver presente. Dados empíricos, entretanto, não apóiam a idéia de que a lei criminal teria qualquer posição central no processo de controle do crime.” Podemos descrever este ponto de argumentação com o termo micropolítica, que pode ser descrito também a partir desta perspectiva sistêmica, que considera o determinismo estrutural de um sistema, ou seja, age a partir da consciência de que qualquer atuação política somente encontra validade, ou funcionalidade, na apropriação minimamente voluntária pelo sujeito sobre quem atuam as forças de intervenção. Por outro lado, de acordo com o pensamento sistêmico, nenhum sujeito produz "saber" sem "ser" e "fazer", ou seja, sem as suas intenções e desejos particulares (que devemos procurar explicitar). Neste sentido, é nosso claro objetivo que os jovens não portem armas nem trafiquem drogas, mas não por isso deixemos de levar em conta a lógica processual da "saída do crime", efeito do estabelecimento de laços sociais em um mínimo de ética (respeito ao outro). O grande problema de algumas políticas de segurança é que elas parecem pretender mudanças radicais "da água para o vinho", o que as torna igualmente violentas. Muitas destas "abordagens imediatistas" não são atividades concretas, mas discursos que trazem explicações insossas a respeito de problemas sociais muito graves, que decorrem das ontologias de nossas culturas urbanas. ${ }^{2}$

Recentemente, uma cidade da região metropolitana de Porto Alegre adotou uma política de prevenção às drogas realizando revistas ao material dos alunos mediante supervisão da brigada militar. Esta alternativa nos parece duplamente inadequada: primeiro, pelo fato de não coibir o uso de drogas, e sim sua presença dentro do território escolar; segundo, por ser uma grave violação dos direitos individuais, o que vem a sugerir ações de resistência não somente por parte de indivíduos contraventores - ou seja, promovendo o aumento da contravenção. Por outro lado, podemos afirmar que a relação com as drogas tida enquanto relação de saúde e de cuidados de si é uma alternativa eficaz? Ainda não existem respostas definitivas para estas perguntas; há apenas a experiência de certas vantagens que elas proporcionam, e a possibilidade de flexibilização de pressupostos que elas trazem.

A primeira etapa também é importante na descrição e análise das possibilidades de abertura do sistema universitário e das suas interações com "o mundo lá fora". Em um momento inicial, para poder fazer a extensão universitária, foi necessária a revisão dos acoplamentos intrínsecos à própria universidade: a entidade central UFRGS e seus próprios subsistemas, graduação, pós-graduação, extensão, pesquisa, estágios e os papéis a que são incumbidos no desenvolvimento das ciências da sociologia, psicologia, comunicação, etc. De fato, pode-se dizer que uma "vontade humana" dirige este longo processo de parcerias múltiplas, no sentido de que a atividade micropolítica foi mais determinante do que concessões e for- 
matos institucionais, diluindo fronteiras de grandes máquinas em uma experimentação trans-institucional a qual, longe de ser um produto acabado, propõe mais e mais experimentações.

\section{TERCEIRO MOVIMENTO: HETEROGENEIDADE TRANS-INSTITUCIONAL}

Ainda que na perspectiva de partilha, em um domínio lingüístico comum, cada subsistema produziu domínios de conhecimento próprios, registrando informação sobre o projeto de maneiras diferentes, dentro de suas próprias referências de trabalho e de convívio. Esta foi a etapa de "formação" dos oficineiros, que teve prosseguimento com o planejamento de oficinas a serem realizadas com um público alvo específico.

Tais informações incluem idéias convergentes e divergentes, neste entendimento da condição de organização de cada sistema por si, por suas próprias determinações e, portanto, de uma abertura à heterogeneidade. Em outras palavras, no momento em que decidimos lidar com o pressuposto de uma co-deriva estrutural entre dois sistemas e não com determinações anteriores e/ou externas, é inevitável lidar com certo grau de descontrole, de imprevisibilidade, e mesmo de aparente desperdício, pois são estas as nossas características humanas que devem ser respeitadas na construção de novas propostas de trabalho trans-institucional. Estas informações foram e continuarão sendo integradas ao sistema "Oficinas da Restinga", funcionando na continuidade dos procedimentos concebidos no projeto.

A idéia é trabalhar com os sujeitos da comunidade na perspectiva de geração de multiplicadores. Foram supridas algumas demandas de formação específicas (técnicas, teóricas, metodológicas) apresentadas pelos oficineiros, com o cuidado de não tornar a tarefa dos acadêmicos estritamente "curricular", preenchendo o lugar de educadores escolásticos. A finalidade é ampliar algumas de suas habilidades e fomentar possíveis propostas para câmbios estruturais e novos acoplamentos.

Com o investimento na autonomia dos agentes comunitários (oficineiros), foram problematizadas algumas das instituições básicas que comumente os orientam, desde a própria definição conceitual de "oficina" (que é instituição nas formas de pensar) até as possibilidades de agenciamento entre as instituições político-administrativas, nas formas de gestão dos sistemas coletivos, escolas, centro comunitários, universidades...

O grupo de oficineiros é um sistema relativamente aberto, distinto em sua organização (sua identidade sistêmica dentro de um meio, a "figura" em seu "fundo") a partir da nossa observação, e pode ser descrito também enquanto um amálgama de redes que se desenvolvem em novas conexões dentro de redes maiores, como as próprias Restinga e UFRGS. Podemos fazer uma cartografia interessante da Restinga em seu acoplamento com a Universidade, ou com o saber acadêmico, onde nos referenciamos e de onde propusemos deslocamentos de papéis aos atores sociais, em suas instituições político-administrativas clássicas, suas 
representações nas agências governamentais (escolas, postos de saúde, centros comunitários, escolas de samba, conselho tutelar, etc).

Os oficineiros construíram para si um campo próprio de relações de poder que os diferencia da "academia" em uma clara disputa de saberes, no que diz respeito a como trabalhar com adolescentes de uma comunidade. Esta questão passa pela reflexão sobre a heterogeneidade de saberes integrados no trabalho, talvez um dos pontos mais importantes na produção de um domínio comum de relações.

Na universidade e, especificamente, no projeto "Oficinas", a multiplicidade de disciplinas ou áreas do saber é uma questão a ser trabalhada tanto em termos práticos quanto teóricos.

Em primeiro lugar a constituição do grupo de trabalho foi por contaminação, e não foram feitas restrições quanto a currículos. Apenas se referia o trabalho com a juventude na Academia. No projeto dos oficineiros, também não, apenas que se pressupunha que se fizessem oficinas com a juventude na comunidade. De um lado, temos psicologia, sociologia, comunicação, artes visuais, e de outro, graffitti, capoeira, dança, cerâmica, música, vídeo, teatro, rádio. Constituímos, portanto, o que alguns chamam transdiciplinaridade, multidisciplinaridade ou interdisciplinaridade.

O que colocamos em questão é a palavra "disciplina", termo polissêmico e com enorme peso simbólico. No seu uso acadêmico, consideramos uma delimitação de uma espécie de campo ou área do saber. Edgar Morin (1996) recorda que muitos dos nossos jargões acadêmicos vêm da física clássica e da engenharia: "campo do conhecimento", "construção do conhecimento", "alicerces da teoria", "base da teoria", "embasamento teórico', "fundamentação teórica", "peso", "solidez", etc. Vivemos em um verdadeiro edifício lingüístico do conhecimento e, como todo edifício, existem áreas delimitadas e sistemas em funcionamento que são montados sobre outros sistemas anteriormente desenvolvidos.

A "área" é um perímetro, uma noção de limite geométrico, e não do cálculo aritmético. No organograma acadêmico, podemos identificar as diferentes áreas do conhecimento, como a matemática, a física, a química, a biologia, a sociologia, a psicologia, a filosofia. Podemos agrupá-las em áreas maiores, como as "ciências humanas", "exatas", "biomédicas", ou subdividi-las em áreas ainda menores, como a "sociologia do trabalho", ou a "psicologia social". Ocorre uma compartimentação verdadeiramente burocrática do trabalho e do saber, desde um determinado ponto de vista de acordo como qual pressupõe-se que separar é importante para conhecer e controlar até mesmo o modo como conhecemos a e agimos sobre o mundo e nós mesmos.

Igualmente, em termos ecológico-cognitivos, o conhecimento é disposto em áreas identificáveis geometricamente, a biblioteca, os livros, os quadros, etc. No entanto, ainda que as disciplinas sejam separadas por áreas, elas sempre estiveram de certa forma interligadas, em diversos níveis e por diversas razões: desde alguma relação intrínseca ao conhecimento (não há física ou engenharia sem matemática e muito menos biologia sem Química) até a necessidade dos especialis- 
tas de juntarem seus percursos de trabalho, seja pelo interesse teórico, seja pela relação prática (postos de saúde, hospitais, empresas, etc.).

Normalmente, os termos "inter", "trans" e "multi" são utilizados com o mesmo significado: um trabalho conjunto de experts de várias áreas... Convencionamos uma diferenciação entre os termos da seguinte maneira: 1) um paciente é atendido por vários profissionais, que não se comunicam: "multidisciplinar"; 2) o paciente é atendido por profissionais que se comunicam em equipe: "interdisciplinar"; 3 ) o paciente é atendido por profissionais de formações diferentes, mas que são guiados por procedimentos e técnicas comuns, a especificidade de cada um é quase que puramente um acessório: "transdiciplinar" (PASSOS; BENEVIDES, 2000).

Em certo momento, tais distinções são necessárias para preservar as referências de onde produzimos nossos discursos. Por outro lado, estas três palavras são assim definidas por nós, em nossos percursos acadêmicos. Em certa altura, a única utilidade de ter claras algumas diferenciações é a possibilidade de desfazêlas efetivamente em nossa forma de raciocínio. Baremblitt (2002), por exemplo, nos diz que a análise institucional pode ser feita por qualquer profissional, pois a instituição é um fantasma que nos encobre a todos. Nesta perspectiva, tudo é uma questão de ponto de vista, e voltamos ao pensamento sistêmico desenvolvido por Maturana e Varela (2001). Eles demonstram, desde noções da Biologia sobre o organismo vivo, que a complexidade do observado intrinsecamente determinada pela complexidade do observador. Tudo é uma questão de perspectiva, da maneira como enxergamos as coisas e somos perturbados, e dentro dos nossos acoplamentos com o meio circundante produzimos nossos domínios relacionais, dentre os quais, os simbólicos. Podemos comparar o que é observado por observadores distintos, estabelecendo padrões graduais de compreensão em escalas compartilhadas.

Dessa forma, nós, acadêmicos de diversas áreas do saber e não acadêmicos estamos nos reunindo para trabalhar em cooperação entre nós e com jovens da comunidade, e no meu ver, a questão disciplinar aí foi ultrapassada. Ultrapassada a academia, não há mais transdisciplinariedade, mas uma atuação trans-acadêmica.

Se vamos realmente pensar em um processo ontológico do grupo que tem desenvolvido este projeto, o nome do grupo poderia ser "juventude e complexidade": consideramos uma visão do todo, mas também retomamos as partes como sistemas são "inteiros" (o todo pode ser unidade, e a parte da mesma forma), agrupados e delimitados em complexos de observadores que dialogam em um espaço de trocas. Acredito que assim podemos todos avançar, cada um com seu ponto de vista enriquecido no encontro com o outro, procurando este domínio simbólico comum de interações.

\section{Notas}

${ }^{1}$ Oficineiros são moradores do bairro que ministram atividades educativas com crianças, jovens e adultos, ocupando espaços educativos alternativos, as oficinas.

${ }^{2}$ Especialmente em tempos de eleição, a mídia invariavelmente apresenta justificativas redutoras, como se as causa de erros pudesse ser apontadas numa administração anterior, em seu afã por defender propostas partidárias demagógicas de "renovação". 


\section{REFERÊNCIAS}

BAREMBLITT, G. F. Compêndio de análise institucional e outras correntes: teoria e prática. Belo Horizonte: Instituto Félix Guattari, 2002.

BOURDIEU, P. O poder simbólico. Rio de Janeiro: Bertrand; Lisboa: Difel, 1989. . Razões práticas: sobre a teoria da ação. Petrópolis: Vozes, 1996.

DELEUZE, G.; GUATTARI, F. Mil platôs: capitalismo e esquizofrenia. Rio de Janeiro: Ed. 34, 1996. v. 3.GUATTARI, F. Caosmose: um novo paradigma estético. Rio de Janeiro: Ed. 34, 1998.

Brasiliense, 1980.

Revolução molecular: pulsações políticas do desejo. São Paulo:

MATURANA, H. A ontologia da realidade. Belo Horizonte: UFMG, 1997.

MATURANA, H.; VARELA, F. A árvore do conhecimento: as bases biológicas da compreensão humana. São Paulo: Palas Athenas, 2001.

MORIN, E. O Método. In: . O conhecimento do conhecimento. Porto Alegre: Sulina. 1996. v. 3.

NUNES, M. K. Restinga, memória dos bairros. Porto Alegre: Prefeitura Municipal de Porto Alegre, 1990.

OBSERVAPOA. Observatório da cidade de Porto Alegre. Disponível em: $<$ http:/ /www.observapoa.com.br>. Acesso em: 15 mar. 2007.

PACHECO, A. et al. Vivenciando a cultura na Restinga. Porto Alegre: UFRGS, 2007.

PASSOS, E.; BARROS, R. B. A construção do plano da clínica e o conceito de transdisciplinaridade. Psicologia: teoria e pesquisa, Brasília, DF, v. 16, n. 1, p. 7179, jan./abr. 2000.

SANTOS, B. S. Pela mão de Alice: o social e o político na pós-modernidade. 9. ed. São Paulo: Cortez, 2003.

VAN SWAANINGEN, R. Controle do crime no século XXI: analisando uma nova realidade. Revista Brasileira de Ciências Criminais, São Paulo, ano 11, v. 42, jan./mar. 2003.

Recebido em: fevereiro/2006

Aceito em: setembro/2006 